\title{
Abelmoschus moschatus extract reverses altered pain and neurohistology of a rat with developmental exposure of fluoride
}

\author{
Kurmeti Sudhakar, Mesram Nageshwar, Karnati Pratap Reddy* \\ Neuroscience lab, Department of Zoology, Osmania University, Hyderabad-500007, Telangana, India.
}

\section{ARTICLE INFO \\ Article history: \\ Received on: $17 / 11 / 2017$ \\ Accepted on: 22/04/2018 \\ Available online: 29/06/2018}

\section{Key words:}

Abelmoschus, Cresyl

violet, Fluoride, $\beta$-amyloid,

Nissl substance,

Neurodegeneration.

\begin{abstract}
Fluoride causes major human health complications and evidence suggests that exposure of fluoride during developmental periods adversely affect neurodevelopment, behavior, and maturity of the brain as these periods are critical for developing stages for CNS. The present study aimed to assess the mechanically induced pain sensitivity, cell morphology, circuitry in terms of neural connections and networks and maturation of neurons under fluorideinduced toxicity with concurrent treatment of protective effects of Abelmoschus moschatus seed extract from day 1 of pregnancy to post-natal day (PND) of a rat with age $30^{\text {th }}$ day. Timed pregnant wistar rats (30) were segregated into six groups, viz. control, sodium fluoride $(\mathrm{NaF})(20 \mathrm{ppm}), \mathrm{NaF}+A$. moschatus aqueous extract (AMAE), NaF + A. moschatus ethanolic extract (AMEE), AMAE, and AMEE and treated for 51 days (21 gestational and 30 postnatal days). On postnatal days 1, 7, 14, 21 and 30, rats were assessed for oxidative stress markers (GSH and GSSG) and neurohistology of the brain. Increased threshold levels to the mechanical stimulus were observed in fluoridetreated rats. Brain stained with Congo red, Cresyl violet and Golgi cox for $\beta$-amyloid, Nissl substance and synaptic connections respectively showed cells become amyloidosis with decreased Nissl substance and decreased number of neuronal connections in NaF exposed rats. Reduced content of GSH and increased GSSG levels $(\mathrm{P}<0.001)$ were also recorded in $\mathrm{NaF}$ treated rats. These alterations were associated with increased production of free radicals and the effect of fluoride on the brain is inversely proportional with age. These changes were ameliorated by supplementation with AMAE and AMEE with anti-oxidant properties, which reduce the production of free radicals from fluoride. Thus, the seed extract of $A$. moschatus had a protective effect over fluoride induced alteration in neural cell maturation, and the establishment of circuitry, mechanical pain sensitivity, and oxidative stress.
\end{abstract}

\section{INTRODUCTION}

Studies have reported various effects of chronic fluorosis on the different organ systems, however, only a few have been on the central nervous system in particular on developmental effects of fluoride. $\mathrm{NaF}$ exposed rabbits' brain histological examinations showed the loss of molecular layer, glial cell layer and Purkinje neurons (Shashi, 2003). Reduced or complete loss of Nissl substance was observed in F intoxicated rabbits (Shashi, 2003) and rats (Shivarajashankara et al., 2002). Developing brain is more prone to fluoride toxicity because of poorly formed protective mechanisms such as blood-brain

\section{${ }^{*}$ Corresponding Author}

Karnati Pratap Reddy, Neuroscience lab, Department of Zoology,

Osmania University, Hyderabad-500007, Telangana, India.

E-mail: pratapkreddyou@gmail.com barrier and anti-oxidant defense. $\mathrm{F}$ mediates the generation of superoxide anion $\left(\mathrm{O}_{2}^{-}\right)$and the supplementary production of hydrogen peroxide, peroxynitrite, and hydroxyl radicals (Hassan and Yousef, 2009). In addition, F affects glutathione levels. This leads to an excessive mitochondrial production of reactive oxygen species (ROS), triggering mutilation to the cellular constituents. The amplified production of ROS causes membrane damage via lipid peroxidation, membrane depolarization, and apoptosis (Zhang et al., 2007). The generation of ROS and lipid peroxidation has been considered to play an important role in the pathogenesis of chronic fluoride toxicity. Recent reports proved that the possible involvement of reactive oxygen species (ROS) in fluoride-induced toxicity (Cao et al., 2015). Oxidative stress has been implicated for its contribution to fluoride associated tissue injury in the liver, kidney, brain, and other organs. Decreased motor abilities, 
thermal and mechanically induced pain responses were noticed in previous research contribution of Mesram et al. (2017) and Sudhakar et al. (2017). Neuropathic pain is a major cause of infirmity, patient's quality of life and interferes with functions relating to CNS (Soler et al., 2007). Different techniques have been used to quantify and assess the development of pain. Among which Randall-Selitto test (Randall and Selitto, 1957), envisioned to serve as a device to evaluate the effect of analgesic agents on the response thresholds to mechanical pressure stimulation (Anseloni et al., 2003).

Prenatal exposure of fluoride results in significant neurochemical alterations in the rats' brain such as significantly intensified brain LPO level while reduced glutathione (GSH) content and superoxide dismutase (SOD), glutathione peroxidase (GPx), and glutathione reductase (GR) activities were decreased markedly (Basha and Madhusudhan, 2010). Fluoride exposed rats displayed various histological changes in the brain, including cell shape, membrane integrity, decreased Nissl granules, de-myelinization, a decrease in the number neural cells, neural connections, circuitry and networks, thickening and disappearance of dendrites (Shivarajashankara et al., 2002; Shashi, 2003; Kamel et al., 2010). We have reported neuroprotective effects of an extract of $A$. moschatus against $\mathrm{F}$ induced motor, nociceptive learning behavior and histological change in the brain of adult rat (Sudhakar et al., 2017).

Recently, researchers have put their attention on the protective effect of natural products against neurodegenerative diseases. The administration of curcumin protect from $\mathrm{NaF}$ induced neurodegeneration (Nageshwar et al., 2017) and quercetin diminished the neuronal death and reduced the oxidative stress in aluminum-induced neurodegeneration in the rat hippocampus (Sharma et al., 2016). Resveratrol was used against fluoride induced neurodegeneration through oxidative stress (Nalagoni and Karnati, 2016). Saha et al. (2016) explored that the leaf extract of Acacia catechu is having in anti-neurogenic and antioxidant properties. Neuroprotective effect of Ocimum sanctum leaf extract was studied in the transgenic Drosophila model of Parkinson's disease (Siddique et al., 2014). All the studies are eventually on adults and no reports are noticed in the literature on protective effects of $A$. moschatus extract during development. In view of this, we have chosen $A$. moschatus plant to protect against fluoride induced neurodegeneration during gestational and early postnatal exposure as it has anti-oxidants. The plant consists of quercetin, rutin, catechin, epicatechin, and procyanidin which have good antioxidant properties. Procyanidin oligomers were showed greater antioxidant property than vitamins $\mathrm{C}$ and $\mathrm{E}$. According to Shui and Peng (2004) quercetin derivatives and (-)-epigallocatechin as major antioxidant compounds in Okra. Quercetin derivatives (quercetin 3-O-xylosyl (1" $\rightarrow 2$ ") glucoside, quercetin 3-O-glucosyl (1" $\rightarrow 6$ ") glucoside, quercetin 3-O-glucoside, and quercetin 3-O-(6"-O-malonyl)glucoside) contributes the major antioxidant property (around $70 \%$ ) of the plant. Different pectic and hemicellulose (xylan, xyloglucan) structures were recently reported in Okra (Sengkhamparn et al., 2009). By the presence of quercetin derivatives and various carbohydrates, Okra extract is involved in eliminating or reducing in the generation of free radicals and thus prevents neurotoxicity from fluoride. The aim of the present study, therefore, is to obtain a reversal in pain response, anti-oxidant nature and histological alterations induced by fluoride ingestion and neuroprotective effects of Okra seed extract against fluoride during developing stages of the nervous system.

\section{MATERIALS AND METHODS}

Adult female Wistar rats (three months old, around 250-300 g body weight) were used. The animals (2 females and 1 male in a separate cage) were kept in standard laboratory conditions with $12 \mathrm{~h} \mathrm{light/dark} \mathrm{periods} \mathrm{at} \mathrm{a} \mathrm{temperature} \mathrm{of} 22$ $\pm 2{ }^{\circ} \mathrm{C}$ for breeding and supplied with dry rat food and drinking water ad libitum. The rats were acclimatized for one week prior to the commencement of the experiment. All experimental protocols were approved by the Ethics Committee of our institution as per CPCSEA No: 383/01/a/CPCSEA. After rat's pregnancy was confirmed, from the first-day pregnancy, the females segregated into six groups and allowed to drink on fluoridated water at the rate of $20 \mathrm{ppm} \mathrm{NaF}$ and also Abelmoschus moshatus seed extract was given to the rats at the rate of $300 \mathrm{mg} \mathrm{kg}^{-1}$ body weight. The plant was identified and authenticated (No. 282) by Taxonomy lab, Department of Botany, Osmania University, Hyderabad, and voucher specimen also submitted for future reference. The plant material (seeds) was extracted with water and ethanol according to the method described in our earlier report (Sudhakar et al., 2017).

\section{Experimental Design}

\begin{tabular}{|c|c|}
\hline Experimental group & Treatment \\
\hline Group I & Received normal tap water \\
\hline Group II & Fed on fluoridated drinking water (20 ppm) \\
\hline Group III & $\begin{array}{c}\mathrm{NaF}(20 \mathrm{ppm})+\text { Abelmoschus moschatus seed aqueous } \\
\text { extract (AMAE) }\left(300 \mathrm{mg} \mathrm{kg}^{-1} \text { b. wt. }\right)\end{array}$ \\
\hline Group IV & $\begin{array}{c}\mathrm{NaF}(20 \mathrm{ppm})+\text { Abelmoschus moschatus seed ethanolic } \\
\text { extract (AMEE) }\left(300 \mathrm{mg} \mathrm{kg}^{-1} \text { b. wt. }\right)\end{array}$ \\
\hline Group V & $\begin{array}{l}\text { Abelmoschus moschatus seed aqueous extract (AMAE) (300 } \\
\qquad \mathrm{mg} \mathrm{kg}^{-1} \text { b. wt.) only }\end{array}$ \\
\hline Group VI & $\begin{array}{l}\text { Abelmoschus moschatus seed ethanolic extract (AMEE) (300 } \\
\qquad \mathrm{mg} \mathrm{kg}^{-1} \mathrm{~b} \text {. wt.) only }\end{array}$ \\
\hline
\end{tabular}

\section{Behavioral tests}

\section{Mechanical hyperalgesia}

The mechanically induced nociceptive withdrawal threshold was assessed by using an apparatus called Randall Selitto electronic algesimeter. The basis for this test is threshold response and stimulus mechanism. The apparatus consists of a pinpoint rod which is used to generate stimulus on the dorsal surface of the hind paw. The maximum force applied was limited to $250 \mathrm{gm}$ (calibrated force) to avoid skin damage. Each experimental rat was exposed to Randall Selitto test and noted down the reads as withdrawal response of paw and expressed in pounds (Randall and Selitto, 1957; Santos-Nogueira et al., 2012). 


\section{Oxidative stress}

\section{Reduced glutathione}

The glutathione content in the brain tissue was estimated by the method of Hissin and Hilf (1976). The method takes advantage of the reaction of GSH with ortho-phthaldehyde (OPT) at $\mathrm{pH} 8$ and of GSSG with OPT at $\mathrm{pH} 12$; GSH can be complexed to $\mathrm{N}$-ethylmaleimide to prevent interference of GSH with measurement of GSSG. GSH reacts with a fluorescent reagent OPT to form a stable, highly fluorescent tricyclic complex which was measured spectrophotometrically at a wavelength of $350 \mathrm{~nm}$ and $420 \mathrm{~nm}$.

\section{Oxidized glutathione}

Determination of glutathione disulfide (GSSG) in the brain tissue by the method of Hissin and Hilf (1976). At measurement of GSSG, GSH was complexed to N-ethylmaleimide (NEM) to form GS-NEM. This is followed by the back extraction of excess NEM from the sample with dichloromethane. GSSG concentration is measured by spectrophotometry by GSH recycling method. Fluorescence at emission $420 \mathrm{~nm}$ was recorded by excitation at $350 \mathrm{~nm}$.

\section{Histology}

\section{Congo red stain}

Congo red stain is used for the detection of amyloid in neurons. Amyloid refers to the abnormal, fibrous, extracellular proteinaceous deposits found in organs such as brain, liver, kidneys, spleen etc. Congo red dye forms nonpolar hydrogen bonds with amyloid and appeared in red and the nuclei in blue. This condition of deposition of amyloid in tissues is known as Amyloidosis. The tissue thickness of sections was 10 microns and was stained with Congo red and counterstained with Gill's hematoxylin. The slides studied under Lawrence digital microscope with 40X (Elghetany et al., 1989).

\section{Cresyl violet stain}

Cresyl violet staining allows for analysis of neuronal morphology and the neuronal population. The Nissl-staining method is based on the interaction of basic dye, cresyl violet with the nucleic acid content of cells. It can bind to the DNA content of the cell nuclei, but also to the RNA that is highly concentrated in RER and ribosomes (Nissl substance) in the cytoplasm. The Nissl staining can specifically stain the cytoplasm of neurons as it is an active site for protein synthesis. This is an advantage of Nissl staining. The sections about $10 \mu$ were stained with cresyl violet stain, coverslipped with mounting medium (DPX) and observed under the microscope with 40X magnification (Pilati et al., 2008).

Golgi cox

Golgi cox stain help us to study of neural cell growth, connections, circuitry, maturation and neuronal networks. Golgi cox staining solution was prepared by mixing of $5 \%$ potassium chromate solution, 5\% potassium dichromate solution and $5 \%$ mercuric chloride solution in equal proportion, brains were preserved in it for 10 days in the dark room. They were washed and preserved in $30 \%$ sucrose solution and made into sections about $10 \mu$ thick on vibratome. These sections were passed through hypo, water, and ammonium solution and dehydrated by graded alcohol baths $(30 \%, 50 \%, 70 \%, 90 \%$ and $100 \%)$. The slides were prepared and observed under a digital microscope with 4X (Gibb and Kolb, 1998).

\section{STATISTICAL ANALYSIS}

Data for all variables were subjected to analyses of variance (ANOVA) to assess the effect of $\mathrm{Na}-\mathrm{F}$ administered to rats, duration of administration. When ANOVA was significant, a t-test was conducted in all possible combinations of experimental groups for individual comparison. The probability of $\mathrm{p}<0.01$ and $\mathrm{p}<0.001$ was considered significant for all evaluations. All data are expressed as mean $\pm \mathrm{SEM}$.

\section{RESULTS}

\section{Mechanical hyperalgesia}

The treated rats have shown significantly reduced response to mechanical pain stimulus compared to control. This effect is higher in day 21 rats than day 30 of fluoride-treated. The simultaneous treatment with AMAE and AMEE along with fluoride-treated rats showed a reverted response to pain stimulus than fluoride alone treated. AMEE showed better efficacy over AMAE.

\section{Reduced glutathione}

Fluoride administered rats showed a significant decrease $(\mathrm{P}<0.01)$ in glutathione (GSH) content as compared to control group. The AMAE and AMEE treated rats along with NaF showed the reverted amount of GSH when compared to $\mathrm{NaF}$ alone treated. The percent of decrease in the content was progressively decreased from day 1 to day 14 and its content was reduced in decreasing in day 21 and day 30 of the fluoride-treated group.

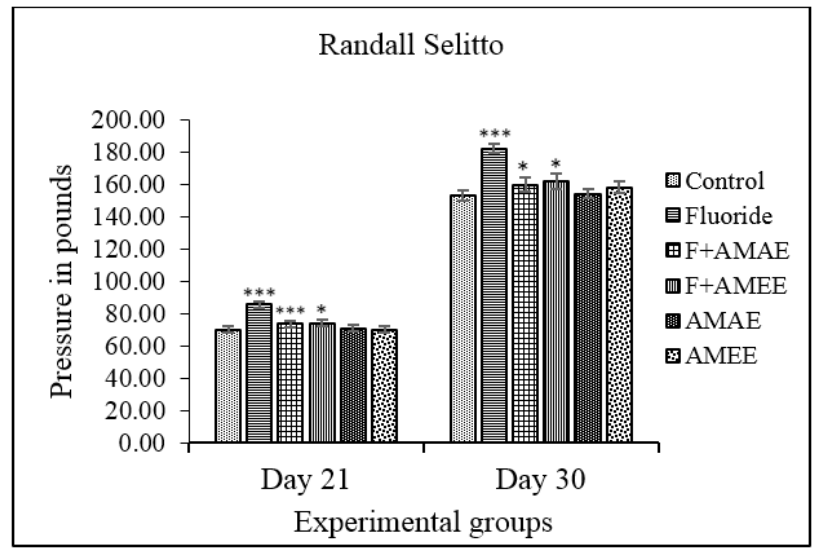

Fig. 1: Protective effects of $A$. moschatus seed extract against $\mathrm{NaF}$ effect on mechanical pain. * for $\mathrm{p}<0.01$ and $* * * \mathrm{p}<0.001$ probability. Each bar graph representing mean \pm SEM. Data are presented as the mean of 5 animals per treatment. Units: Pain response was expressed as Pressure in pounds.

\section{Oxidized glutathione}

Increased GSSG levels were found in NaF administered rats with increasing age from day 1 to day 14 with compared to the respective age of control group. The increase in the GSSG levels from day 21 to day 30 were not significant. In AMAE and AMEE 
treated rats against $\mathrm{NaF}$ showed decreased levels of GSSG when compared to $\mathrm{NaF}$ received rats.

\section{Congo red stain}

Cells without any protein aggregations and plaques were seen in histologically examined brain of congo red stained sections in control rat brain. While in $\mathrm{NaF}$ treated rats showed aggregations which may be amyloid proteins or lead to the development of plaques along with altered cell structure. These kinds of aggregations were found to be very less in number and cell with normal round shape in AMAE and AMEE treated groups compared to $\mathrm{F}$ treated individuals.

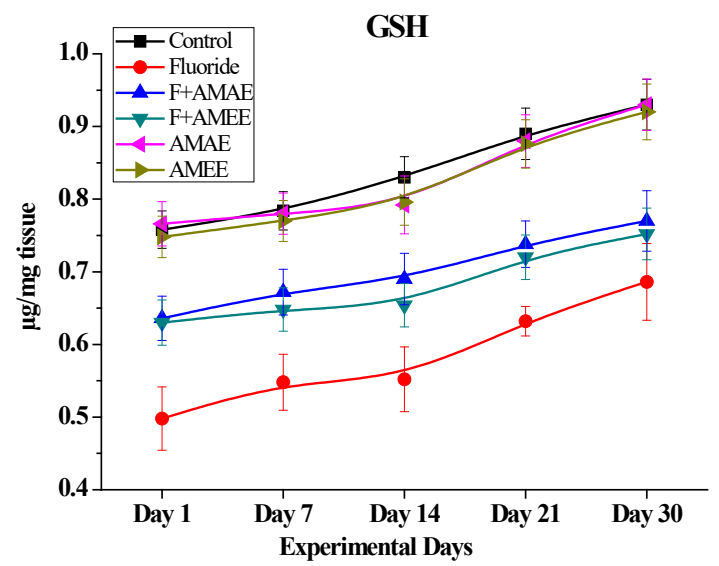

Fig. 2: Protective effects of $A$. moschatus seed extract to NaF exposure effect on GSH content. $\mathrm{p}<0.01$ probability was considered for all groups. Data expressed as mean \pm SEM. GSH content was expressed in terms of $\mu \mathrm{g} / \mathrm{mg}$ tissue. Data are presented as the mean of 5 animals per treatment.

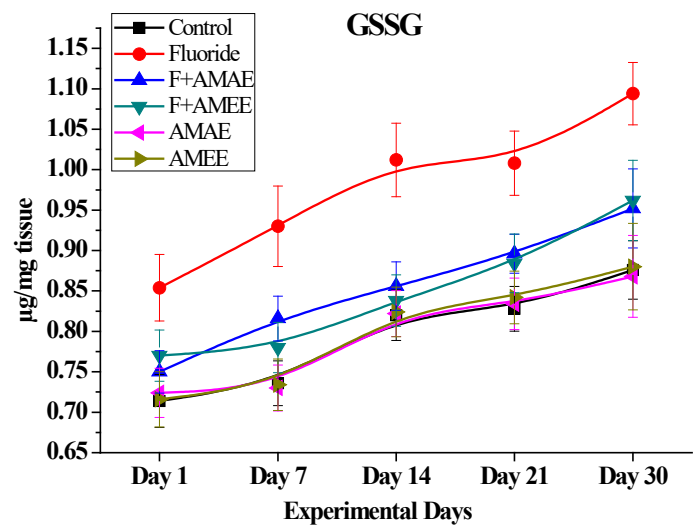

Fig. 3: Protective effects of $A$. moschatus seed extract towards NaF exposure effect on GSSG levels. $\mathrm{p}<0.01$ probability was considered for all groups. GSSG levels were expressed in terms of $\mu \mathrm{g} / \mathrm{mg}$ tissue. Data expressed as mean $\pm \mathrm{SEM}$. Data are presented as the mean of 5 animals per treatment.

\section{Cresyl violet stain}

Significant pathological changes were noticed in the neurodegenerative assay of cresyl violet stain as $\mathrm{NaF}$ group was perceptibly altered neuronal cell morphology, population and decreased Nissl granules (lightly stained cells). These alterations were obviously progressed in NaF treated group from day 1 to 30 .
These all changes were reverted to oral administration of AMAE and AMEE towards $\mathrm{NaF}$ toxicity.

\section{Golgi Cox}

The analysis of Golgi cox stained neurons from both cortical and sub cortical regions of the brain showed a decrease in the size of the cell body, in a number of branches (dendrites), in length of branches (dendrites and axon), neural circuitry and networks in $\mathrm{NaF}$ fed rats with compared to control group. These changes were reported severely on day 1 , gradually progressed from day 7 to day 14 and reduced in the alterations could be found in day 21 and 30 . All aforesaid alterations were reverted to normal on the treatment of AMAE and $\mathrm{AMEE}$ against $\mathrm{NaF}$.

\section{DISCUSSION}

In the present study, we demonstrated that the neurotoxic effects of $\mathrm{NaF}$ on developing rats' brain and protective effects of Abelmoschus moschatus seed extract here off. Free radicals are usually maintained in balance by the body antioxidant defense system, but with an excessive production of free radicals generate oxidative cell damage. This oxidative damage may be due to immobilization of reactive molecules in the brain cells and increases the rate of lipid peroxidation with the release of free radicals inside the neural cells. $\mathrm{NaF}$ mainly acts through the generation of excessive free radicals and which leads to the destruction of membrane lipids and overall anti-oxidant status of the brain. The brain is the rich source of polyunsaturated fatty acids which makes more prone to oxidative stress. Moreover, the developing brain doesn't have completely developed antioxidant system and blood-brain barrier (BBB) which makes them furthermore susceptible to oxidative stress. Dietary antioxidants cooperate with the body enzymes to protect the brain from free radical damage. A. moschatus having antioxidants which helps in hepato-protective (Hu et al., 2014), anti-diabetic (Sabitha et al., 2011), antiulcer (Olorunnipa et al., 2013), anticancer (Gul et al., 2011), anti-inflammatory, laxative, anti-hyperlipidemic, antifungal and analgesic activities (Anil and Neeraj, 2017). In this study, we conducted mechanical pain response test, oxidative stress markers such as GSH and GSSG and histopathological studies (Congo red stain, cresyl violet stain, and Golgi cox stain) to evaluate $\mathrm{NaF}$ neurotoxic effects during pre- and post-natal exposure and as well neuroprotective effects of seed extract of $A$. moschatus.

In $\mathrm{NaF}$ treated rats, nociceptors may get damage and/or weak functioning state take more mechanical pressure to respond pain stimulus. This may be because of inhibitory effects of ROS, inhibition of NF- $\kappa B$ which a key role in the reduced function of nociceptors in $\mathrm{NaF}$ received rats (Nageshwar et al., 2017). AMAE and AMEE treated rats against $\mathrm{NaF}$ showed decreased in the strength of stimulus to respond to Randall Selitto set up. The possible reason for this is seed extract have anti-oxidant properties thus help in the elimination of free radicals from brain which ultimately improves the function of receptors. These reports are similar to that of curcumin as a protective agent towards $\mathrm{NaF}$ intoxication (Nageshwar et al., 2017), and also with Okra extract as reported earlier on adult rats (Sudhakar et al., 2017). 


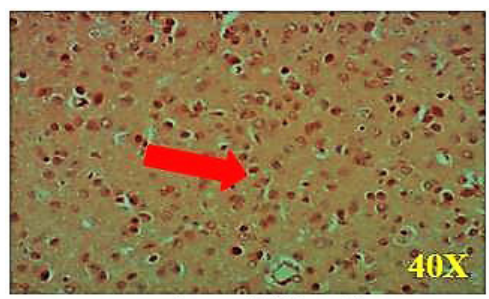

Control (Day 1)

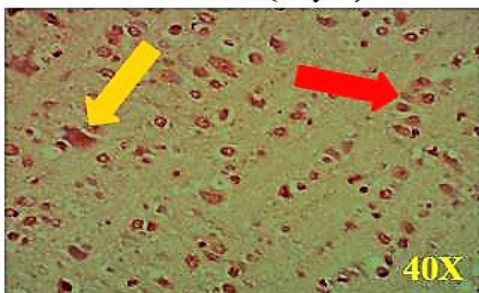

F + AMEE (Day 1)

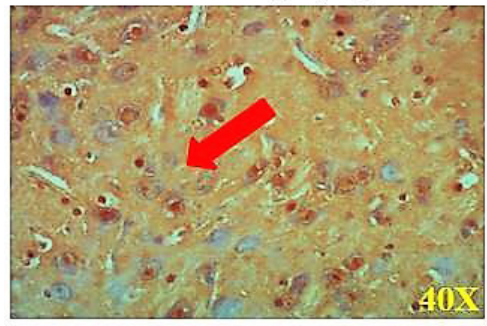

Control (Day 7)

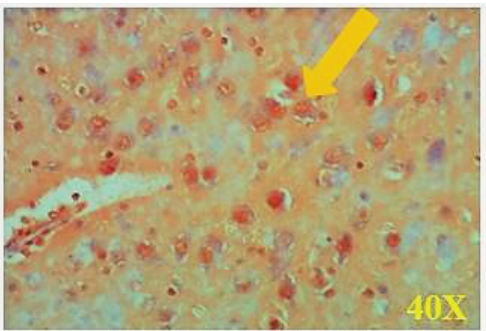

F + AMEE (Day 7)

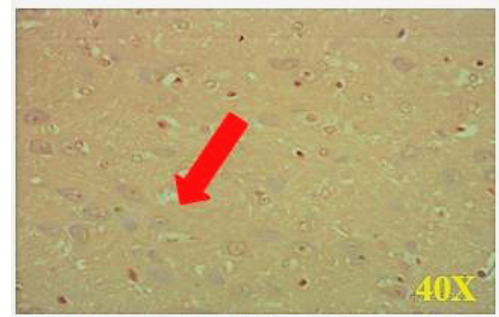

Control (Day 14)

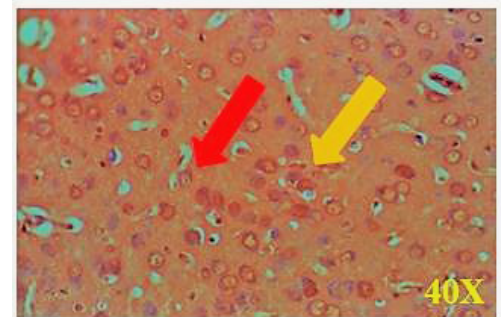

F + AMEE (Day 14)

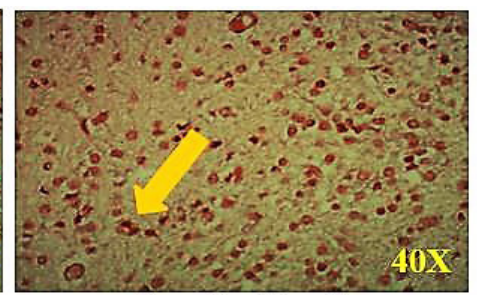

Fluoride (Day 1)

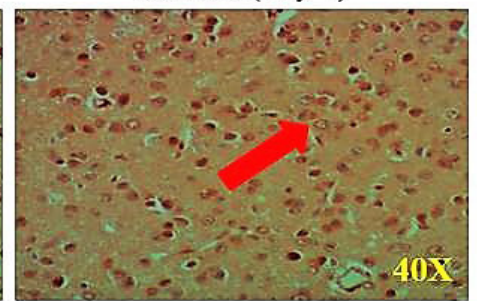

AMAE (Day 1)

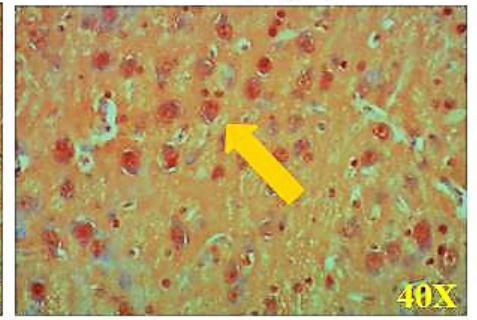

Fluoride (Day 7)

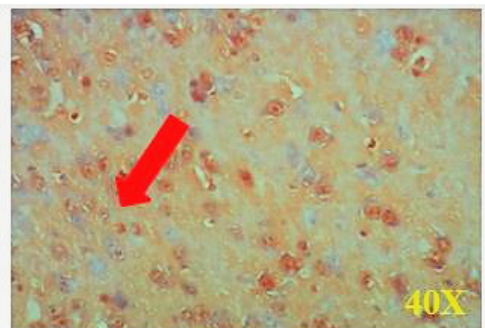

AMAE (Day 7)

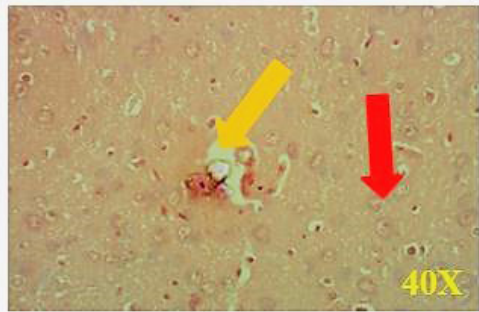

Fluoride (Day 14)

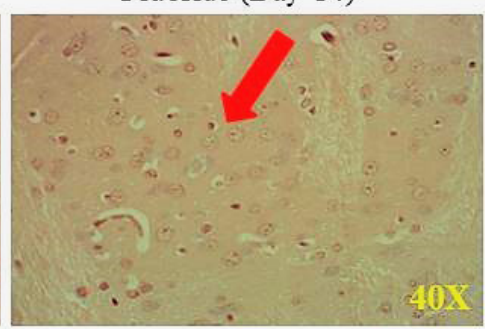

AMAE (Day 14)

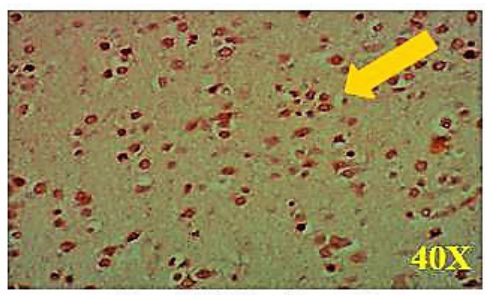

$\mathrm{F}+\mathrm{AMAE}$ (Day 1)

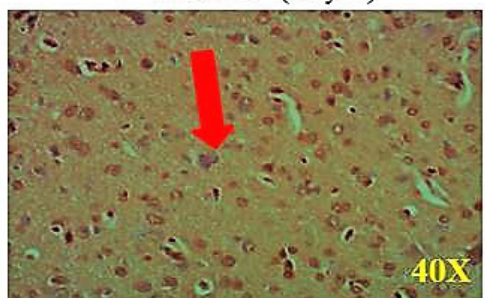

AMEE (Day 1)

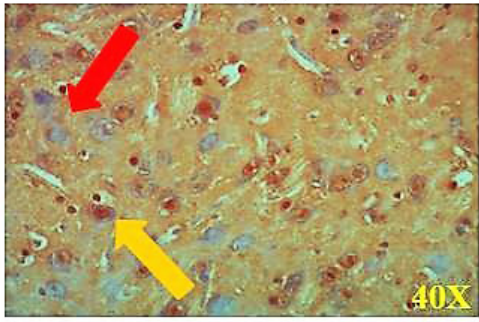

F + AMAE (Day 7)

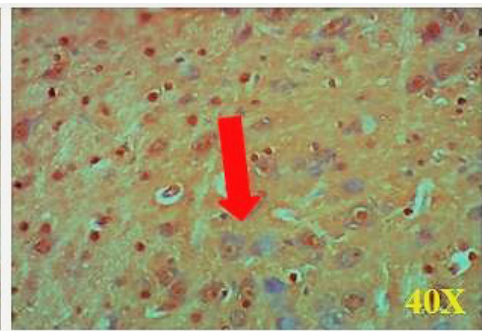

AMEE (Day 7)

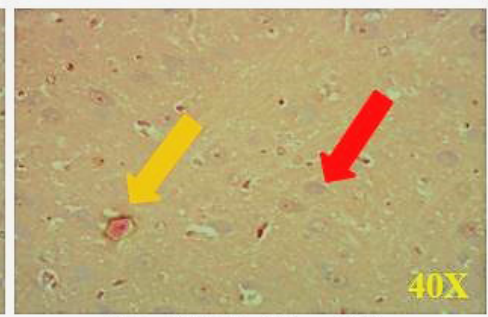

F + AMAE (Day 14)

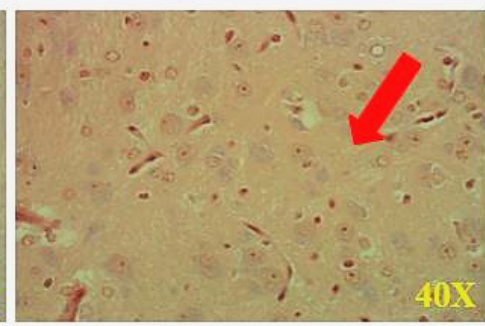

AMEE (Day 14) 

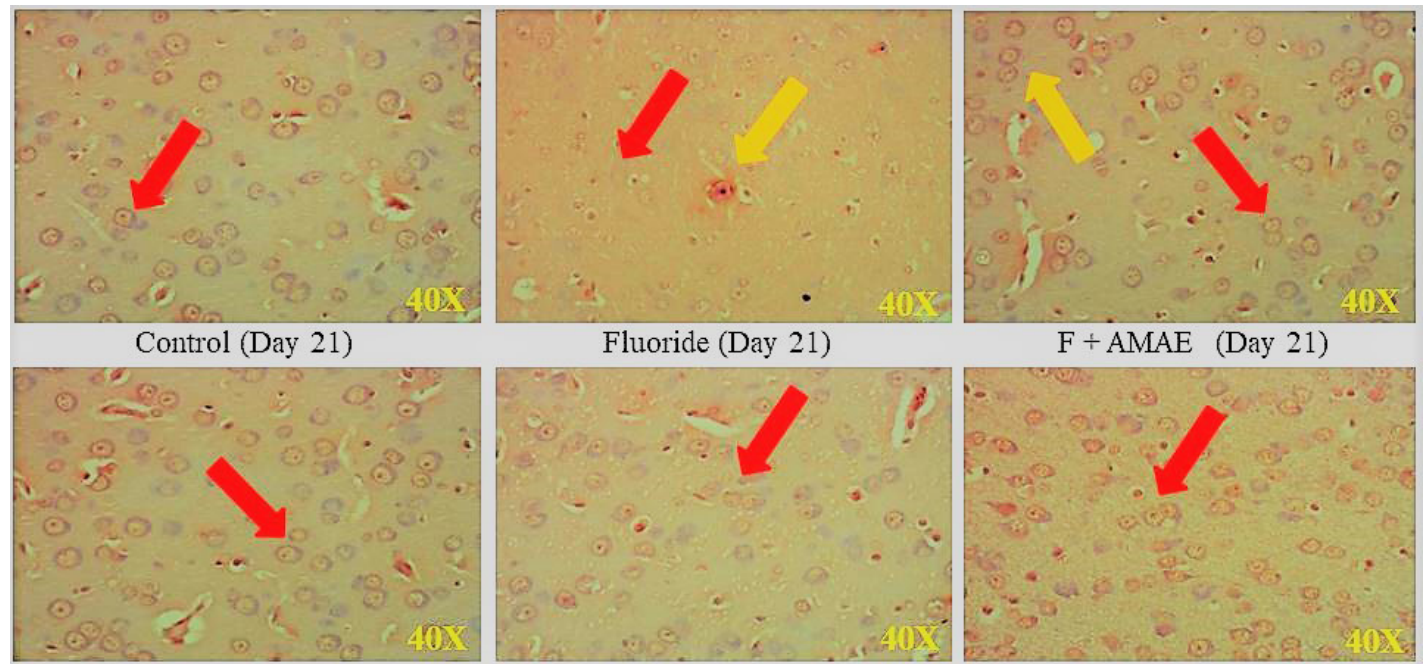

F + AMEE (Day 21)

AMAE (Day 21)

AMEE (Day 21)

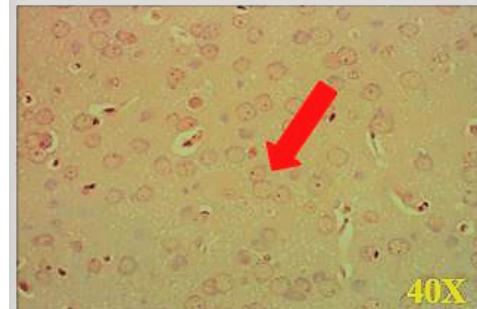

Control (Day 30)

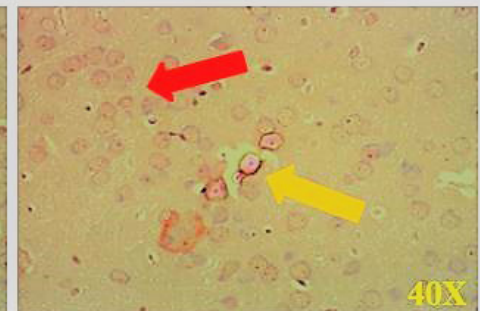

Fluoride (Day 30)

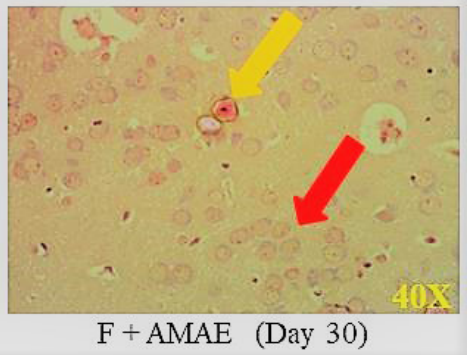

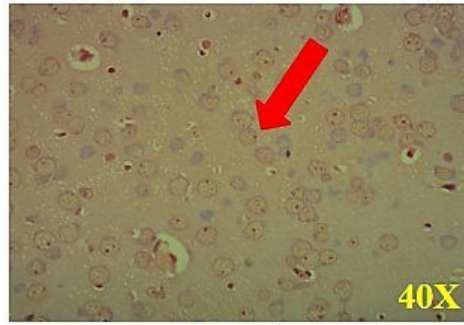

F + AMEE (Day 30)

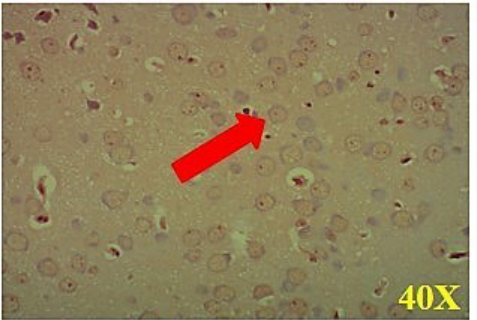

AMAE (Day 30)

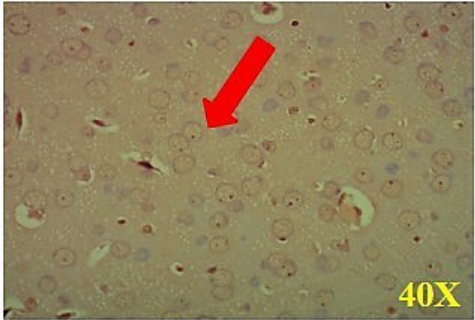

AMEE (Day 30)

Fig. 4: Cerebral cortex region of rat brain stained with Congo red stain. Protective effect of $A$. moschatus seed extract on rat brain exposed to NaF. Normal cells with round shape and cell membrane, stained with blue colored were found in control rat brain sections which are indicated by a red color arrow mark. Yellow colored arrow mark showing the cells which were with the destructing membrane, swelling and undergoing necrosis were shown in NaF received group of rats. NaF+AMAE and $\mathrm{NaF}+\mathrm{AMEE}$ treated rat brain sections were found normal (40X Olympus microscope).

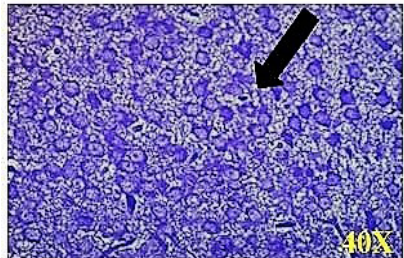

Control (Day 1)

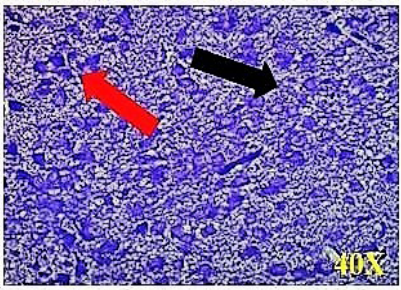

F + AMEE (Day 1)

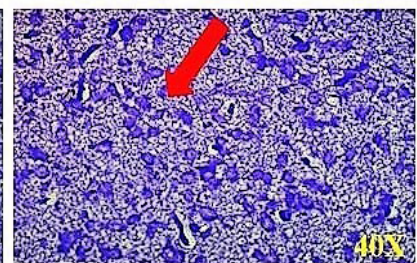

Fluoride (Day 1)

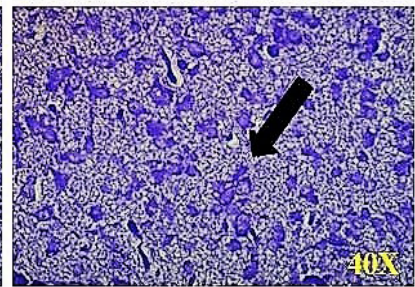

AMAE (Day 1)

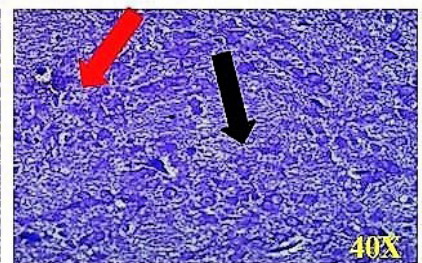

F + AMAE (Day 1)

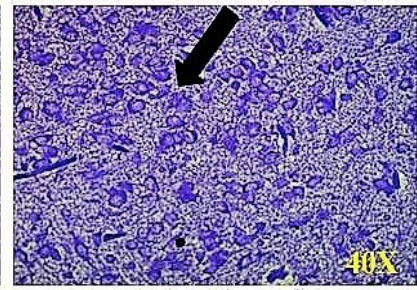

AMEE (Day 1) 


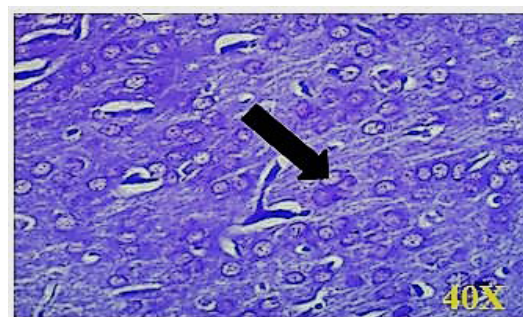

Control (Day 7)

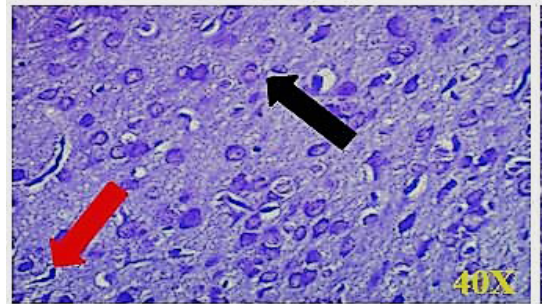

F + AMEE (Day 7)

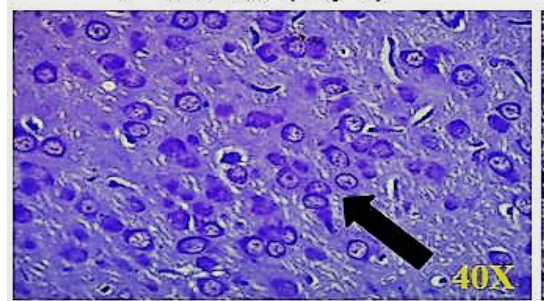

Control (Day 14)

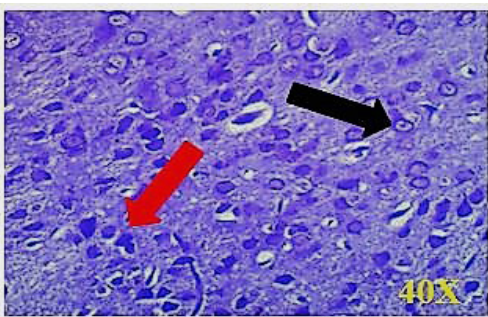

Fluoride (Day 7)

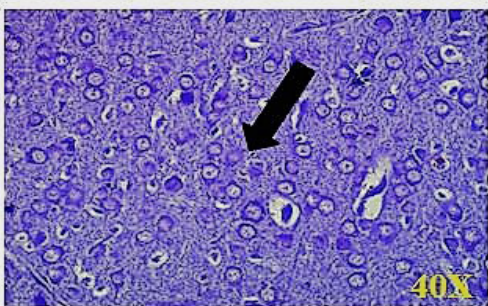

AMAE (Day 7)

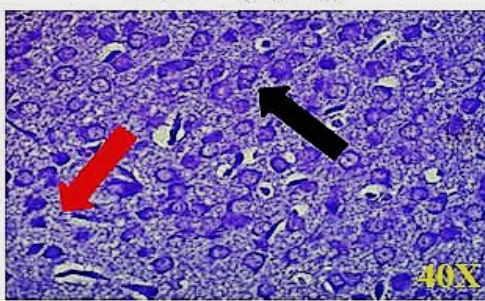

Fluoride (Day 14)

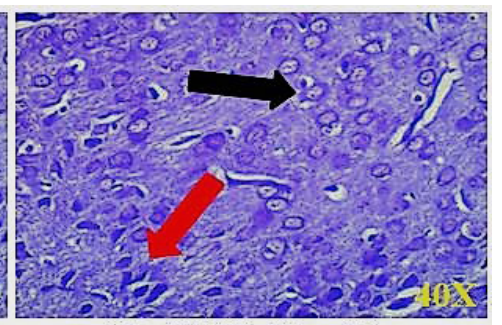

F+AMAE (Day 7)

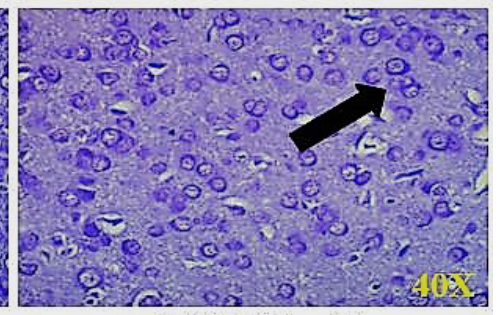

AMEE (Day 7)

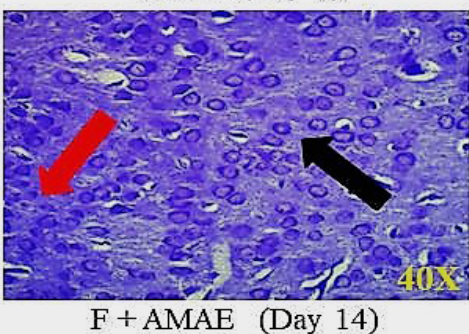

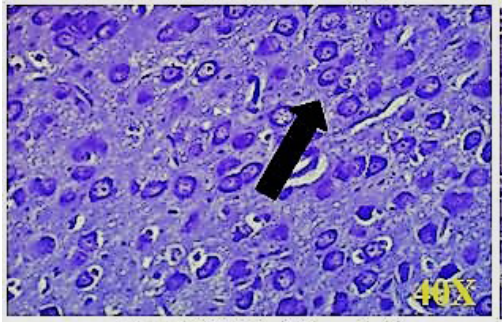

F + AMEE (Day 14)

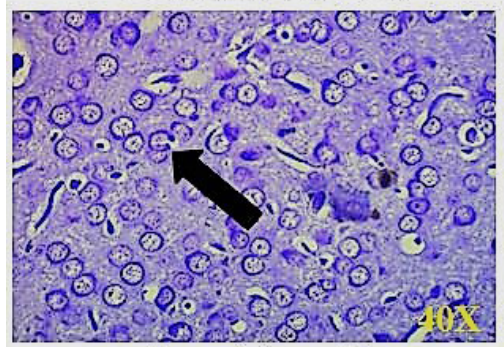

Control (Day 21)

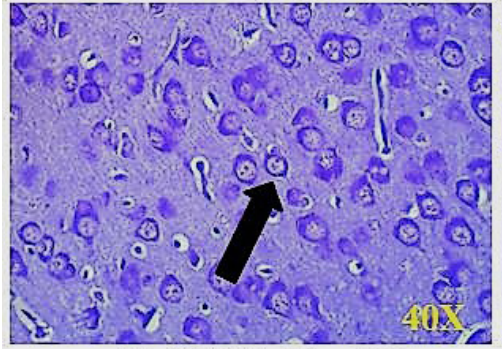

F + AMEE (Day 21)



AMAE (Day 14)

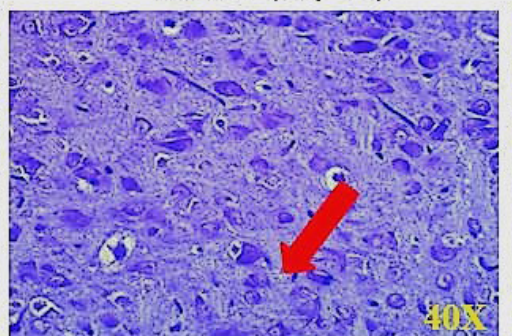

Fluoride (Day 21)

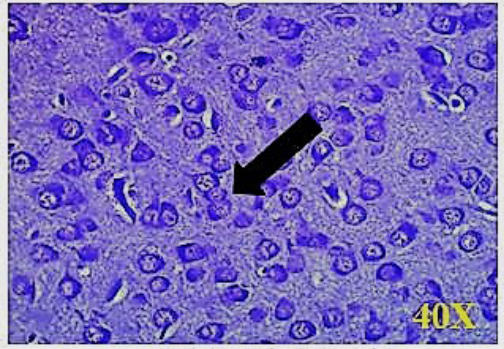

AMAE (Day 21)

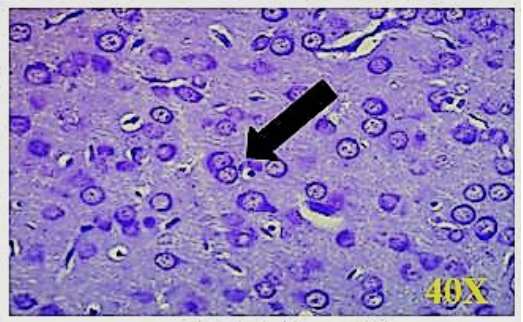

AMEE (Day 14)



$\mathrm{F}+\mathrm{AMAE}$ (Day 21)

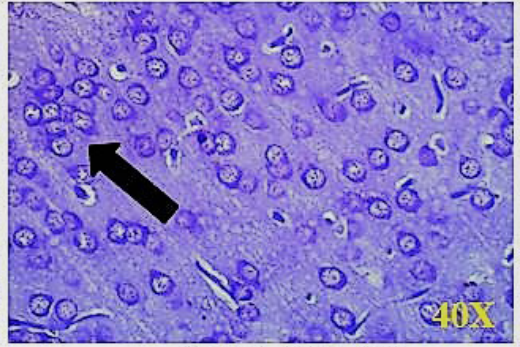

AMEE (Day 21) 

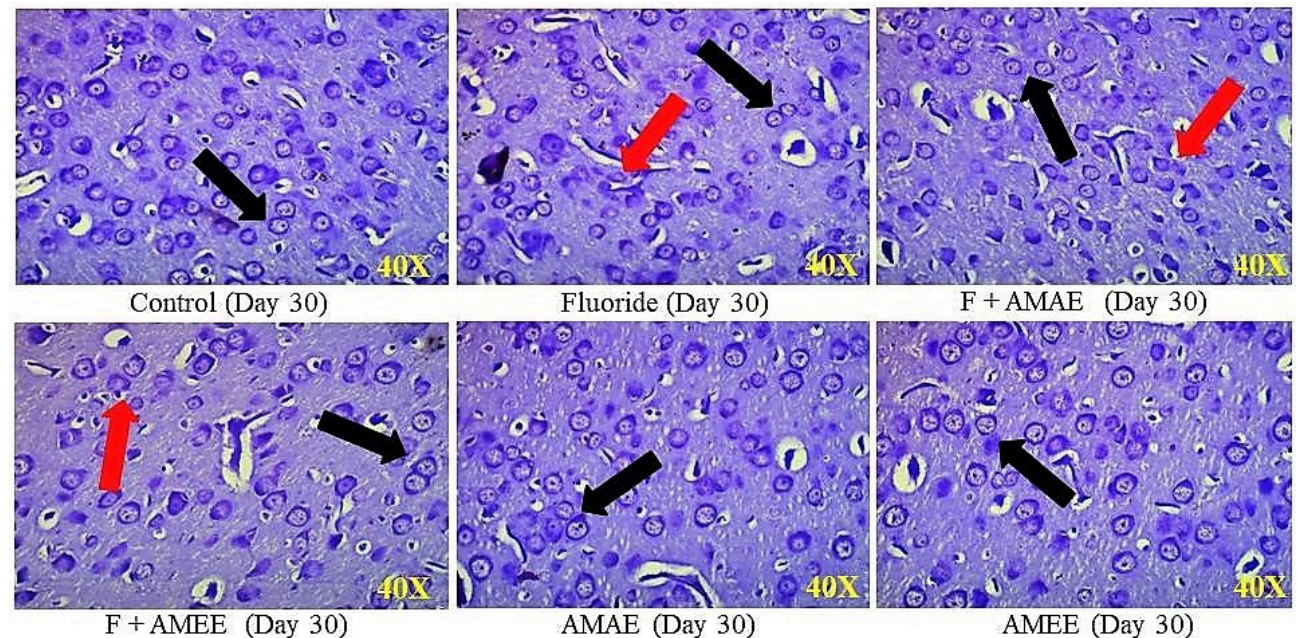

Fig. 5: Cresyl violet stained rat brain (cerebral cortex region). Protective effect of $A$. moschatus seed extract on rat brain exposed to NaF. Normal cells with round shape, healthy cell membrane and clearly visible Nissl granules in the cells. Black colored arrow mark indicating them. Red colored arrow mark showing the cells with the destructing membrane, the altered shape of the cell and decreased granules of Nissl, undergoing necrosis were shown in NaF received group of rats. NaF+AMAE and $\mathrm{NaF}+\mathrm{AMEE}$ treated rat brain sections were shown as reverted earlier mentioned alterations (40X magnification).

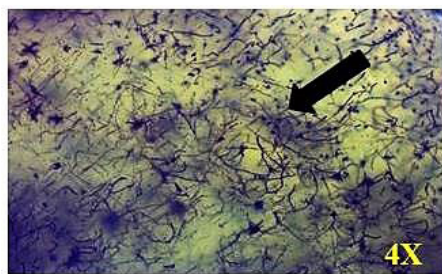

Control (Day 1)

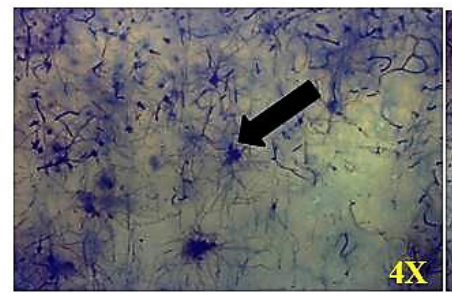

F + AMEE (Day 1)

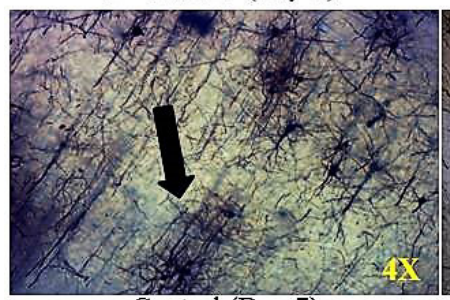

Control (Day 7)

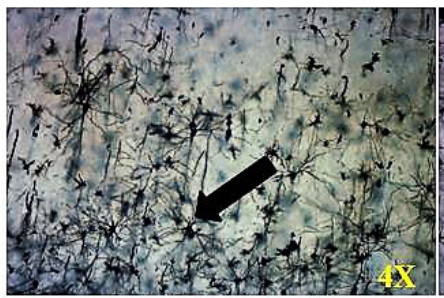

F + AMEE (Day 7)

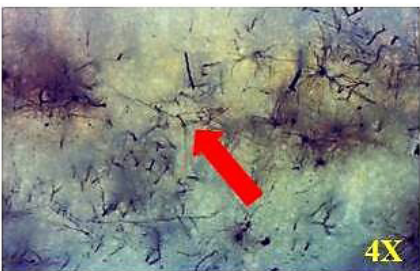

Fluoride (Day 1)

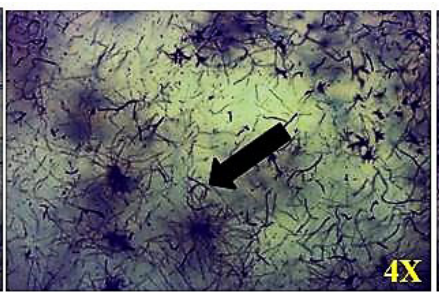

AMAE (Day 1)

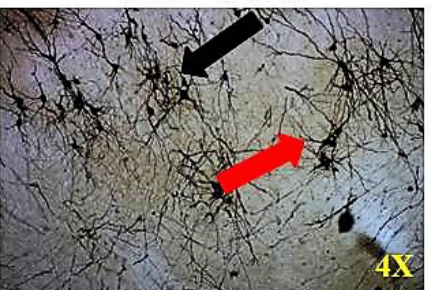

Fluoride (Day 7)

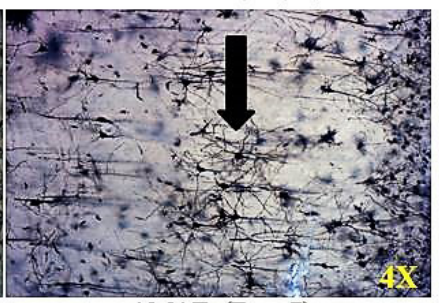

AMAE (Day 7)

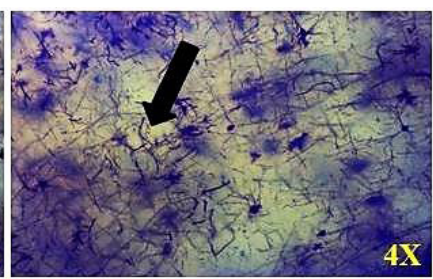

F + AMAE (Day 1)

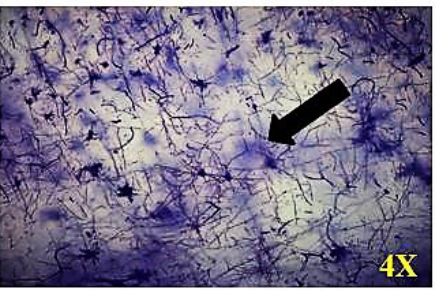

AMEE (Day 1)

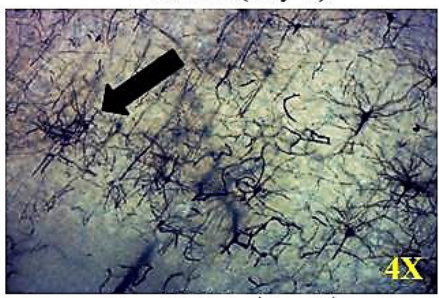

F + AMAE (Day 7)

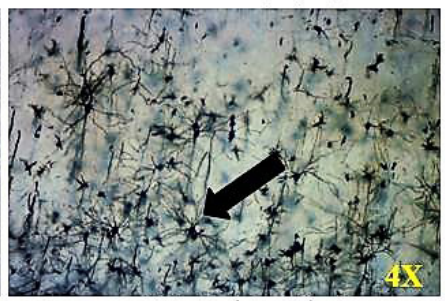

AMEE (Day 7) 


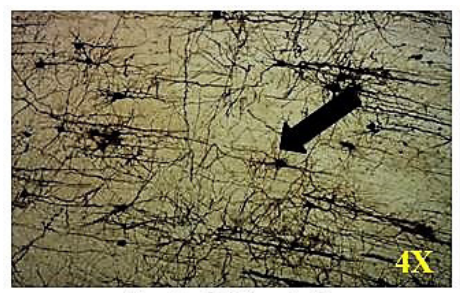

Control (Day 14)

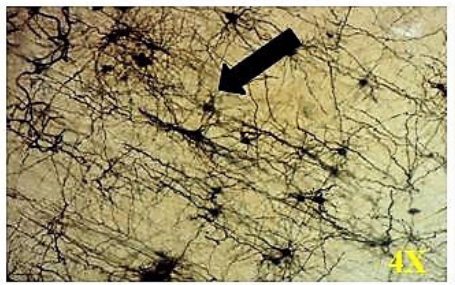

F + AMEE (Day 14)

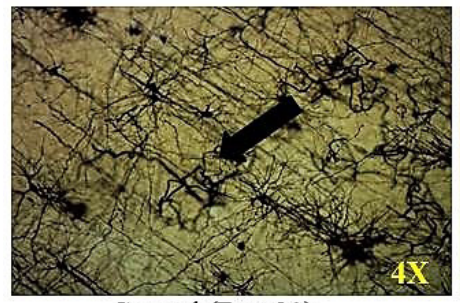

Control (Day 21)

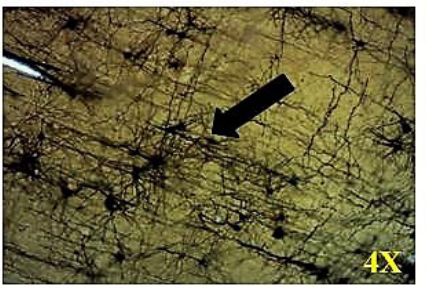

F + AMEE (Day 21)

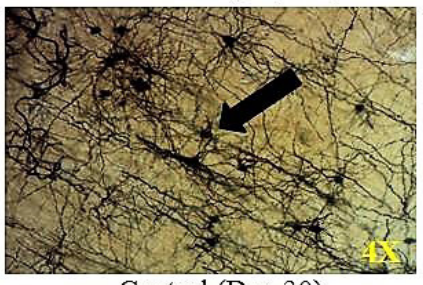

Control (Day 30)

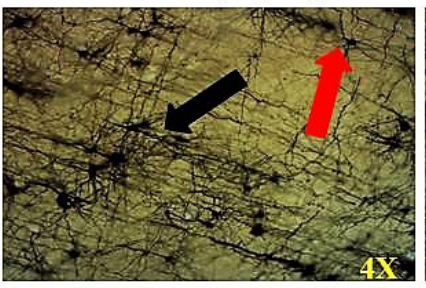

F + AMEE (Day 30)

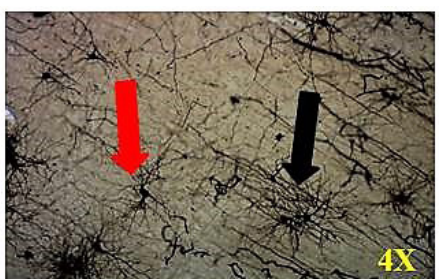

Fluoride (Day 14)

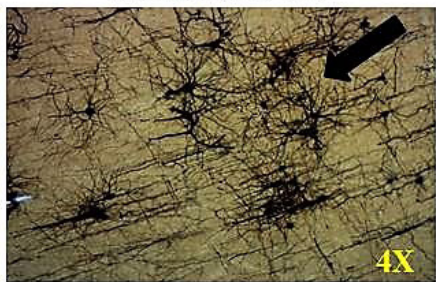

AMAE (Day 14)

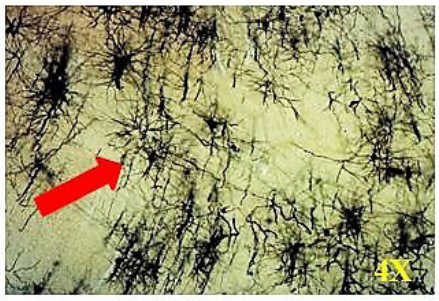

Fluoride (Day 21)

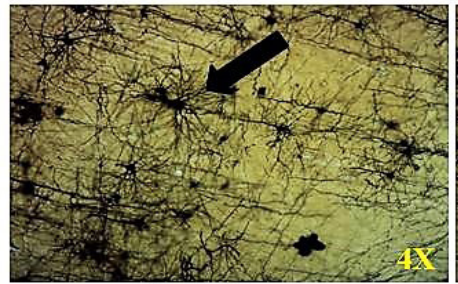

AMAE (Day 21)

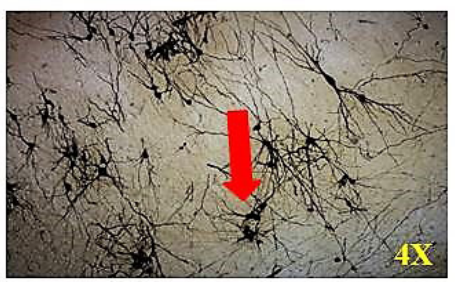

Fluoride (Day 30)

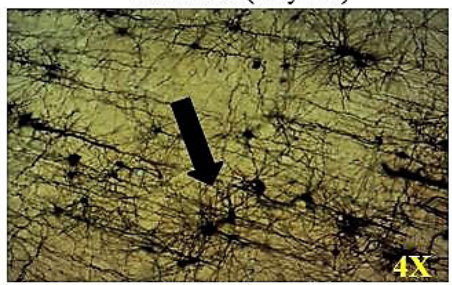

AMAE (Day 30)

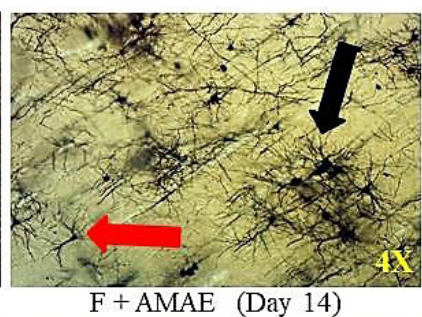

F + AMAE (Day 14)

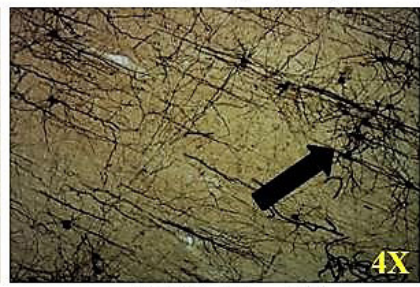

AMEE (Day 14)

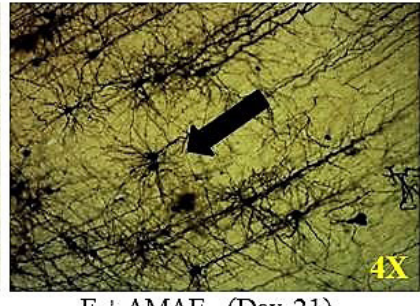

F + AMAE (Day 21)

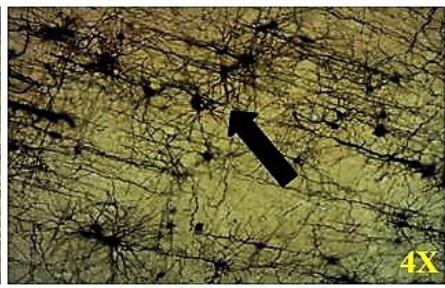

AMEE (Day 21)

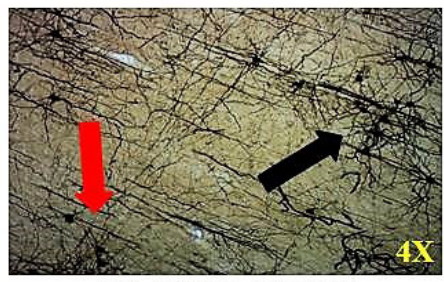

F + AMAE (Day 30)

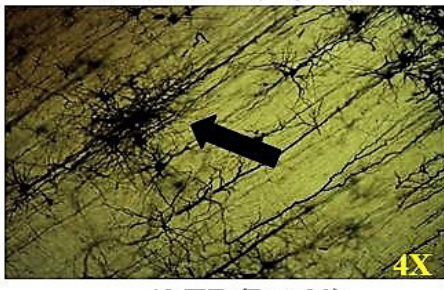

AMEE (Day 30)

Fig. 6: Photomicrograph of Golgi cox stained sections of rat brain (cerebral cortex and sub cortex). Protective effect of $A$. moschatus seed extract on rat brain exposed to NaF. In control rats, neural cells with a normal size of the cell body, number of branches (dendrites), length of branches (dendrites and axon), neural circuitry and networks were typical whereas they were decreased in $\mathrm{NaF}$ fed rats with compared to control group. Black colored arrow mark is showing the typical circuitry and networks. Red color arrow mark is showing the cells which were altered in terms of earlier named characteristics. NaF+AMAE and NaF+AMEE treated rat brain sections were shown in reverted to earlier mentioned alterations (4X magnification).

The GSH:GSSG ratio used as a marker of oxidative stress, which arises due to various distortions. While GSH levels tended to decrease, GSSG levels were increased in NaF fed rats.
The effect of NaF on developing brain is progressively increased with increasing age from day 1 to day 14 as they were not with well-developed anti-oxidant and BBB barrier mechanisms. 
Decreased in the content of GSH was observed up to 14 days and further reduced decrement was found on day 21 and 30 as they maturing, develop the earlier said protective mechanisms. In $\mathrm{NaF}+\mathrm{AMAE}$ and $\mathrm{NaF}+\mathrm{AMEE}$ treated rats content of GSH and levels of GSSG were reverted. In an earlier report of Flora et al. (2009), decreased GSH:GSSG was found in fluoride treated rats. As fluoride is a chemically active ionized element, it may affect oxygen metabolism and induce oxygen free radicals which play a role in diminishing cognitive ability processes such as learning and memory. Moreover, fluoride binds antioxidants in the body such as N-acetyl cysteine (NAC), glutathione (GSH) and other free-radical destroying enzymes thus triggering oxidative stress which leads to cell damage (Anuradha et al., 2000). In the developing brain absence and/or poorly developed a compensatory antioxidant system with the presence of oxidative stress due to increased free radicals plays a great role in the initiation of damage of nerve cells membrane especially via increased lipid peroxidation (Ghiselli et al., 2000; Gao et al., 2009). The increased LPO levels on $\mathrm{NaF}$ intoxication were reverted to treatment with Okra extract in developing brain (Sudhakar et al., 2018).

The main histological alterations were seen in $\mathrm{NaF}$ treated group are a change in shape of the cell, size of the cell body, amount of Nissl substance, amyloid-like aggregations, branching patterns such as a number of branches arising from the cell body, length of branches, circuitry in terms of connections and networks. Among some of the more severe on day 1 pups, those include shape and size of cell and networks, others are more profound in day 21 and 30 rats and those are aggregations. The brain areas particularly cerebral cortex, cerebellum white matter and ventricles around choroid plexuses were found with hemorrhage in the brain of rats exposed to high $\mathrm{NaF}$ for a long duration. Heba et al. (2010) reported neurodegenerative changes in $\mathrm{NaF}$ exposed rats, mainly in their pyramidal cells of Ammon's horn of hippocampus. The pyramidal cells showed atrophy and necrosis. Nerve cells of cerebral cortex showed neurofilaments accumulation in the cytoplasm and the axons, central chromatolysis, edema, and neuronophagia. Hippocampus and cerebral cortex are two major components which involved in learning and memory process (Vianna et al., 2000). These regions are most affected in $\mathrm{NaF}$ intoxication and as a result affect the overall behavior of animal (Varner et al., 1998).

In summary, fluoride produces more amount of free radicals which interact with phospholipid layer of neurons. Due to incompletely developed defense system of developing brain, it is unable to provide protection against $\mathrm{NaF}$. This leads to imbalanced oxidative stress. As result neural cells become paralyzed, thus neurodegeneration follows. PND 1 to 14 rats treated with NaF were displayed more pronounced alterations than PND 21 and 30. Because of poorly developed protective mechanisms in early postnatal pups, the $\mathrm{F}$ effect is more. When we supplement with AMAE and AMEE, these may remove free radicals and stabilize the normal chemical milieu of the brain. Thus the structure, shape and overall morphology of brain was protected from $\mathrm{NaF}$ intoxication. It is also observed that AMEE has better efficacy over AMAE against $\mathrm{F}$ neurotoxicity.

\section{CONCLUSION}

There are very few studies on developing brain of rats which are prenatally exposed to $\mathrm{NaF}$ and continued until the age of post-natal 30 days as well protecting measures with natural agents. The experimental data of this report clearly showed that the developing brain is much sensitive to $\mathrm{NaF}$ toxicity as it has no protective mechanisms. The main protective mechanisms are anti-oxidant status and BBB which were not well established in developing and young rats (PND 1 to 14) make them more prone to $\mathrm{NaF}$ neurotoxicity. The products which possess antioxidant nature are useful in reducing the production of free radicals from $\mathrm{NaF}$, thus provide beneficial effects against $\mathrm{NaF}$ neurotoxicity. AMAE and AMEE are rich sources for quercetin and its derivatives which reduce the production of free radicals and provide rich nutritional value to the diet. AMEE showed good results over AMAE. Hence, the study concludes that the possible reason for reduced fluoride toxicity is the removal of free radicals with a parallel treatment of AMAE and as well as AMEE.

\section{ACKNOWLEDGMENTS}

K. Sudhakar acknowledges CSIR, New Delhi, India for awarding SRF. Authors are also grateful to UGC-DSA-II, FISTUGC-DST F526/2015/DSA-1 for partial financial support and K. Pratap Reddy also acknowledges to BSR mid-career grant.

\section{CONFLICT OF INTERESTS}

There are no conflicts of interest.

\section{REFERENCES}

Anil TP, Neeraj SV. Phytopharmacology of Abelmoschus moschatus medik: A review. Int J Green Pharm, 2017; 11 (4):S648-S653.

Anseloni VC, Ennis M, Lidow MS. Optimization of the mechanical nociceptive threshold testing with the Randall-Selitto assay. J Neurosci Methods, 2003; 131:93-97.

Anuradha C, Kanno S, Hirano S. Fluoride induces apoptosis by caspase-3 activation in human leukemia HL-60 cells. Arch Toxicol, 2000; $74: 226-230$

Basha PM, Madhusudhan N. Pre and post-natal exposure of fluoride induced oxidative macromolecular alterations in developing central nervous system of rat and amelioration by antioxidants. Neurochem Res, 2010; 35(7):1017-1028.

Cao J, Chen J, Xie L, Wang J, Feng C, Song J. Protective properties of sesamin against fluoride-induced oxidative stress and apoptosis in kidney of carp (Cyprinus carpio) via JNK signaling pathway. Aquatic Toxicol, 2015; 167:180-190.

Elghetany MT, Saleem A, Barr K. The congo red stain revisited. Ann Clin Lab Sci, 1989; 19(3):190-195.

Flora SJS, Megha M, Deepshikha M. Co-exposure to arsenic and fluoride on oxidative stress, glutathione linked enzymes, biogenic amines and DNA damage in mouse brain. J Neurolog Sci, 2009; 285:198-205.

Gao Q, Liu Y, Guan Z. Decreased learning and memory ability in rats with fluorosis: increased oxidative stress and reduced cholinesterase activity in the brain. Fluoride, 2009; 42(4):277-285.

Ghiselli A, Serafini M, Natella F, Scaccini C. Total antioxidant capacity as a tool to assess redox status: critical view and experimental data. Free Radic Biol Med, 2000; 29:1106-1114.

Gibb R, Kolb B. A method for vibratome sectioning of Golgi cox stained whole rat brain. J Neurosci Methods, 1998; 79(1):1-4.

Gul MZ, Bhakshu LM, Ahmad F, Kondapi AK, Qureshi IA, Ghazi IA. Evaluation of Abelmoschus moschatus extracts for antioxidant, 
free radical scavenging, antimicrobial and antiproliferative activities using in vitro assays. BMC Complement and Altern Med, 2011; 11(64):1-12.

Hassan HA, Yousef MI. Mitigating effects of antioxidant properties of black berry juice on sodium fluoride induced hepatotoxicity and oxidative stress in rats. Food Chem Toxicol, 2009; 47(9):2332-2337.

Heba S, El-lethey, Kamel MM, Shaheed I. Neurobehavioral toxicity produced by sodium fluoride in drinking water of laboratory rats. J Am Sci, 2010; 6:54-63.

Hissin PJ, Hilf R. A fluorometric method of oxidised and reduced glutathione in tissues. Anal Biochem, 1976; 74:214-226.

Hu L, Yu W, Li Y, Prasad N, Tang Z. Antioxidant activity of extract and its major constituents from Okra seed on rat hepatocytes injured by carbon tetrachloride. Bio Med Res Int, 2014; 1-9.

Kamel MM, El-Lethey H, Shaheed I, Kamel G. Black tea forestalls sodium fluoride induced neurobehavioral toxicity in laboratory rats. J Am Sci, 2010; 6(12):1655-1673.

Mesram N, Nagapuri K, Banala RR, Nalagoni CR, Karnati PR. Quercetin treatment against $\mathrm{NaF}$ induced oxidative stress related neuronal and learning changes in developing rats. J King Saud Univ Sci, 2017; 29:221-229.

Nageshwar M, Sudhakar K, Reddy NCS, Reddy KP. Neuroprotective effects of curcumin on sodium fluoride induced behavioural and enzymatic changes in brain and muscles of rat. J Environ Biol, 2017; 38:675-681.

Nalagoni CSR, Karnati PR. Protective effect of resveratrol against neuronal damage through oxidative stress in cerebral hemisphere of aluminum and fluoride treated rats. Interdisci Toxicol, 2016;9(2):78-82.

Olorunnipa TA, Igbokwe CC, Lawal TO, Adeniyi BA, Mahady GB. Anti-helicobacter pylori activity of Abelmoschus esculentus L. moench (Okra): an in vitro study. Clin Microbiol, 2013; 2(7):1-5.

Pilati N, Barker M, Panteleimonitis S, Donga R, Hamann M. A Rapid Method Combining Golgi and Nissl Staining to Study Neuronal Morphology and Cytoarchitecture. J Histochem and Cytochem, 2008; 56(6):539-550.

Randall LO, Selitto JJ. A method for measurement of analgesic activity on inflamed tissue. Arch Int Pharmacodyn Ther, 1957; 111(4):409419 .

Sabitha V, Ramachandran S, Naveen KR, Panneerselvam K. Antidiabetic and antihyperlipidemic potential of Abelmoschus esculentus (L.) Moench in streptozotocin-induced diabetic rats. J Pharm and Bioallied Sci, 2011; 3(3):397-402.

Saha MR, Dey P, Begum S, Bratati D, Tapas KC, Sarkar DD et al. Effect of Acacia catechu (L.f.) willd on oxidative stress with possible implications in alleviating selected cognitive disorders. PLoS One, 2016; 11(3):p.e0150574.

Santos-Nogueira E, Redondo Castro E, Mancuso R, Navarro X. Randall-Selitto Test: A New Approach for the Detection of Neuropathic Pain after Spinal Cord Injury. J of Neurotrauma, 2012; 29(5):898-904.

Sengkhamparn N, Verhoef R, Schols HA, Sajjaanantakul T, Voragen AG. Characterization of cell wall polysaccharide from Okra (Abelmoschus esculentus (L.) Moench). Carbohydr Res, 2009; 344(14):1824-1832.
Shah BN, Seth AK, Maheshwari KM, Desai RV. Screening of Abelmoschus esculentus fruits for its analgesic activity. Pharmacol Online, 2010; 2:17-21.

Sharma D, Wani W, Sunkaria A, Kandimalla RJ, Sharma RK, Verma D et al. Quercetin attenuates neuronal death against aluminuminduced neurodegeneration in the rat hippocampus. Neurosci, 2016; 324:163-176

Shashi A. Histopathological investigation of fluoride-induced neurotoxicity in rabbits. Fluoride, 2003; 36:95-105.

Shivarajashankara YM, Shivashankara AR, Bhat PG, Rao SM, Rao SH. Histological changes in the brain of young fluoride-intoxicated rats. Fluoride, 2002; 35:12-21.

Shui G, Peng LL. An improved method for the analysis of major antioxidants of Hibiscus esculentus Linn. Chromatogr A J, 2004; 1048 (1):17-24.

Siddique YH, Faisal M, Naz F, Jyoti S, Rahul. Role of Ocimum sanctum leaf extract on dietary supplementation in the transgenic Drosophila model of Parkinson's disease. Chin J of Natural Med, 2014; 12(10):777-781.

Soler MD, Sauri-Ruiz J, Curcoll-Gallemi ML, Benito Penalva J, Opisso-Salleras E, Chamarro-Lusar A, Vidal-Samso J. Characteristics of chronic neuropathic pain and their relationship with psychological wellbeing in spinal cord injury patients. Rev Neurol, 2007; 44:3-9.

Sudhakar K, Nageshwar M, Pratap Reddy K. Protective effect of Okra, Abelmoschus moschatus seed extract on developing brain of rats during pre- and post-natal fluoride exposure. Int J Pharm Sci Res, 2018; 9(4):1000-1011.

Sudhakar K, Nageshwar M, Pratap Reddy K. Seed extract of Abelmoschus moschatus medik reverses NaF-induced behavioral changes through neurodegeneration and oxidative stress in brain of rat. Asian J Pharm Clin Res, 2017; 10(10):165-171.

Varner J, Jensen K, Horvath W, Issacon R. Chronic administration of aluminium fluoride or sodium fluoride to rats in drinking water: Alterations in neuronal and cerebrovascular integrity. Brain Res, 1998; 784:284-298.

Vianna M, Alonso M, Viola H, Quevedo J, de Paris F, Furman M, Levi de Stein M, Medina J, Izquierdo I. Role of hippocampal signaling pathways in long-term memory formation of a non-associative learning in the rat. Learn Mem, 2000; 7:333-340.

Zhang M, Wang A, He W, He P, Xu B, Xia T, et al. Effects of fluoride on the expression of NCAM, oxidative stress, and apoptosis in primary cultured hippocampal neurons. Toxicol, 2007; 236(3):208-16.

How to cite this article:

Sudhakar K, Nageshwar M, Reddy KP. Abelmoschus moschatus extract reverses altered pain and neurohistology of a rat with developmental exposure of fluoride. J App Pharm Sci, 2018; 8(06): 094-104. 